Aus der Medizinischen Klinik und Poliklinik der Universität Münster (Direktor: Prof. Dr. W. H. Hauss)

\title{
Schlußwort zur Diskussionsbemerkung von Jack G. Makari
}

$$
\text { Von }
$$

\section{S. Ritter}

Der von MAKaRI 1955 angegebene immunologische Krebstest wurde mit gleichartiger Treffsicherheit bisher nur von BuRRows bestätigt. HaCKETT u. GaRdonyr erreichten bei 47\% der untersuchten Tumorpatienten positive Ausfälle. Auf die Anwendung des Tests bei Patienten mit anderen Leiden haben sie verzichtet. Musso u. BRUN fanden von 186 Uterushörnern $88 \%$ auf Normalserum und nur $17,6 \%$ auf Tumorpatientenserum positiv reagierend.

$\mathrm{Zu}$ einer negativen Beurteilung kamen weiter MoEwen, MaAss u. Schniewind, Wrtria, Teichmann u. SchneEweiss sowie Rittrk.

Die weiteren von MaKaRI im Zusammenhang mit einer erfolgreichen Nachprüfung seiner Reaktion genannten Autoren haben zwar immunologische Tumorprobleme bearbeitet, sich aber nicht mit diesem diagnostischen Krebstest beschäftigt, was für BARUAH und GRACE u. LeносZKY auch MaAss in seiner Erwiderung auf die Kritik Makakis hervorgehoben hat. FrNK u. Mitarb. haben ebenfalls keinen Antigennachweis im Serum tumorkranker Mensohen oder Tiere versucht.

SevLJaGin hatte zwar ein Antigen im Blutplasma von Kaninchen mit Brown-PearceTumoren nachgewiesen, in einer nachfolgenden Arbeit 1961 aber mitgeteilt, daß es sich nicht um spezifische Tumorantigene handele. Bei MoLkov liegt keine eigene experimentelle Arbeit, sondern eine Literaturübersicht vor, in der MaKaRIs Arbeiten zitiert sind.

Comes kommt zu keiner Entscheidung hinsichtlich der Spezifität des Makari-Tests und hält auch MoEwens negative Kritik für unwiderlegt.

Selbstverständlich ist eine wirksame Sensibilisierung nur bei den Tieren anzunehmen, deren Uterushörner nach vorheriger Neutralisierung mit Normalserum noch mit Serum von Tumorpatienten reagieren. Ob die Tiere nach der Vorbehandlung mit Tumorextrakt - und nur darauf bezieht sich die von MakzaRI angegriffene „,Definition" - für den Test bereit waren, galt es gerade zu prüfen, das wurde nicht vorausgesetzt. Und deshalb kamen auch nur Seren von diagnostisch klaren Patienten zur Anwendung.

Fast alle Nachprüfer haben sich bemüht, Makarrs Technik exakt zu reproduzieren. Sie haben auch auf die vielfachen Fehlermöglichkeiten hingewiesen.

In den Arbeiten zur Originalmethode ist die jetzt von MAKaRI herausgestellte niedrige Tumorextraktdosierung bei der Injektion der Tiere nicht angegeben, was auch MAASS betont. Bei Borrows findet sich ebenfalls kein Hinweis dafür. HaCKETT u. GARdonyi haben mit stärkeren Konzentrationen gearbeitet. MUsso u. BRUN haben bei einer kleinen Gruppe ihrer Meerschweinchen mit höherer Dosierung sogar relativ bessere Resultate gehabt.

$\mathrm{Ob}$ es sich bei Tumorantigenen um reine Polysaccharide handelt, dürfte noch offen sein. Im übrigen ist zu den Fehlermöglichkeiten und der allgemeinen Problematik der Reaktion in meiner hier zur Debatte stehenden Arbeit (1962) Stellung genommen worden.

\section{Literatur}

(soweit sie nicht in der Diskussion von MLAKaRI schon aufgeführt ist)

MaAss, H.: Klin. Wschr. 41, 102 (1963).

Musso, E., et R. BRUN: Oncologia (Basel) 16, 273-280 (1963).

ShviJagin, V. JA.: Vop. Onkol. 7, H. 1, 57-60 (1961).

Wittig, G., B. Teichinann u. U. SchneEwhiss: Acta biol. med. germ. 8, 274-289 (1962).

Dr. S. RITTER,

Medizinische Klinik und Poliklinik der Univensität,

44 Münster/Westf. 